\title{
The Application of Identification Strategies in Sci-fi Movie Avatar
}

\author{
Gengqing Chen ${ }^{1} \&{\mathrm{Yan} \mathrm{Li}^{2}}^{2}$ \\ ${ }^{1}$ Qinhuangdao Branch of Northeast Petroleum University, Qinhuangdao, China \\ ${ }^{2}$ Shanghai Chengying Co.Ltd \\ Correspondence: Gengqing Chen, Department of Basic Courses, Qinhuangdao Branch of Northeast Petroleum \\ University, 550, West Hebei Street, Haigang District, Qinhuangdao, Hebei, 066004, China. E-mail: \\ steviv@126.com
}

Received: January 11, 2015 Accepted: February 3, 2015 Online Published: March 29, 2015

doi:10.5539/ijel.v5n2p123 URL: http://dx.doi.org/10.5539/ijel.v5n2p123

\begin{abstract}
The study of rhetoric is a complicated discipline with a long history. As a representative of new rhetoric, Kenneth Burke develops the rhetoric from the persuasion to identification and other points of view. Identification is concerned with the functions of language in identification, persuasion and inducement of emotions, values and actions. This paper aims to explore Burke's theory of identification and its three basic ways of identification and its successful application in the sci-fi movie Avatar. As an important form of persuasion, movie is also rhetoric which makes it possible for the audience to accept its values, emotions, attitudes, etc, thus the identification among the characters themselves and the identification among the directors, characters and its audience could be achieved. Through analyzing how these three basic ways of identification are applied in the movie, the author concludes that they play an important role in persuading the audience and contribute a lot to the wide appeal of the movie.
\end{abstract}

Keywords: identification, identification strategies, Avatar

\section{Kenneth Burke's Identification}

As one of the most famous rhetoricians of new rhetoric in western counties, Kenneth Burke defines the rhetoric as: "The use of language as a symbolic means of inducing cooperation in beings that by nature respond to symbols" (Burke, 1969, p. 47). But he expands the definition of rhetoric by introducing the concept of "identification" into new rhetoric. While admitting that the core of rhetoric is persuasion, he goes far beyond persuasion as he says "we might well keep in mind that a speaker persuades an audience by the use of stylistic identification. His act of persuasion may be for the purpose of causing the audience to identify itself with the speaker's interests to establish rapport between himself and his audience (Burke, 1962, p. 46). According to Burke, the root of identification lies in the concept of "substance". We build ourselves through various substances and through common emotions, attitudes, aspirations, values and other properties, two entities can be united and become consubstantial. Just as Burke says: "to identify A with B is to make A 'consubstantial' with B” (Burke, 1966, p. 192). Burke puts forward three ways of identification, namely, identification by sympathy, identification by antithesis and identification by inaccuracy.

\subsection{Identification by Sympathy}

This method can be used as a means which emphasizes the common emotion among people. Sympathy is considered as a feeling that could bind people together when they have common affections. Take a student's application for subsidies for example, when a student wants to apply for the students' subsidies, he has to tell his audiences that his family is so poor that he can't afford his tuitions. Then moved by his miserable fate, his audiences decide to give the only opportunity to him. Here the student identifies his condition with the requirement of applying for the students' subsidies through winning the other's sympathy.

Lastly, one had better take himself/herself as one of the audience if one wants to persuade his/her audience effectively. For example, when Obama runs for the President of the USA, in order to win the votes from the black people, he emphasizes her origin of black. He can identify himself with the farmers in the aspect of race. Finally, he can earn more chances to win the election. Identification by sympathy plays a positive role in contacting with the others, for example, education in school and the circle one is involved in. 


\subsection{Identification by Antithesis}

Identification by antithesis is a most urgent form of reaching congregation through segregation (Chang Changfu, 1998, p. 161). The segregation here means the antithesis. They congregate together because they have the same enemy. Jiang Jieshi and Mao Zedong are ideologically oppositional for a long time. However, during the Anti-Japanese War, they united together to resist against Japan. The exterior enemy obviously is the force of congregation for these two opposite communities. Antithesis universally consists in human beings' daily lives. The identification by antithesis reflects the philosophical view of Burke.

\subsection{Identification by Inaccuracy}

Identification by inaccuracy derives from situations in which it goes unnoticed. In this case, identification is used to persuade at an unconscious level (Foss, 1986, p. 193). For example, Burke points out that when people are driving their cars, they always mistake the engine power as their own ability; in other words, it is the engine that makes the wheel rolling, but not their feet on clutch. Once leaving the car, they could only walk by their own feet. Hence, Burke's identification by inaccuracy reminds people of examining his cognition and adjusting the wrong region of their cognition. In this way, they can identify their own abilities with outward objects more exactly.

\section{The Application of Identification in Avatar}

The director of Avatar Cameron himself, the author of several fictions, has also ever appeared in the scene as an actor. For this reason, he can well understand the inner worlds of all his audiences or readers. Thus he can manage to strike a chord among his audiences. Finally, he identifies his motive with his followers' expectation in a further step. However, he goes further by identifying his cognition and vision with the audience in his great work Avatar. Without doubt, the identification is all achieved wonderfully among the directors, actors and audiences.

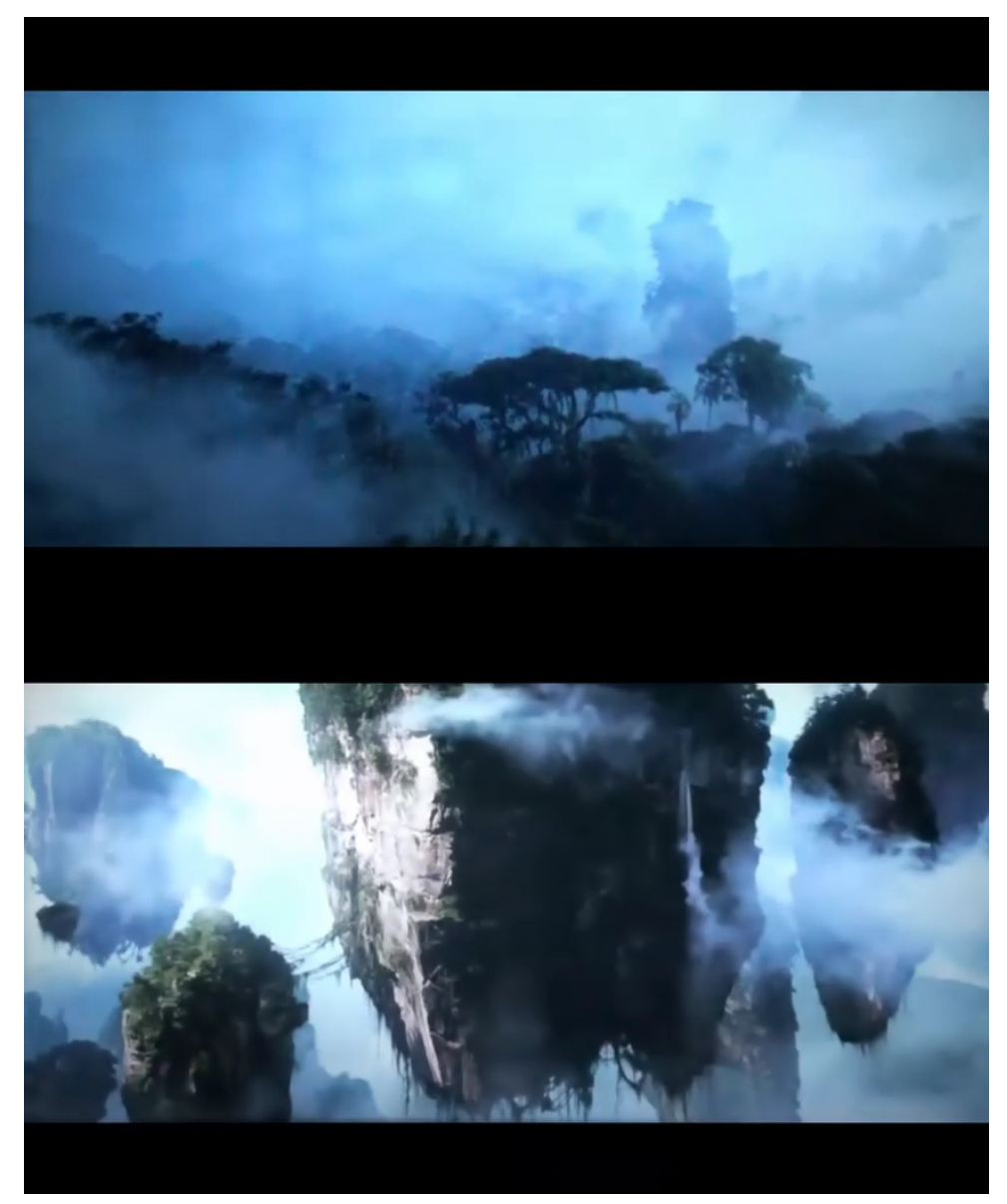

At the very beginning, the mythical scenes place audiences in a wonderland, especially with the 3D spectators. The extremely long shot contributed to the scenes which presents audiences with some spectacular views. As an audience, I can associate the beautiful nature with all living things. In the ideal Pandora, the inhabitants will live 
peacefully and harmoniously in the place that somewhat looks like paradise. Specifically speaking, the scene is the nonverbal rhetors which can make the audience agree with its intention behind the scenes. Thereafter, nothing but the fantastic scenes conquered its mass audience that can be interpreted as follows:

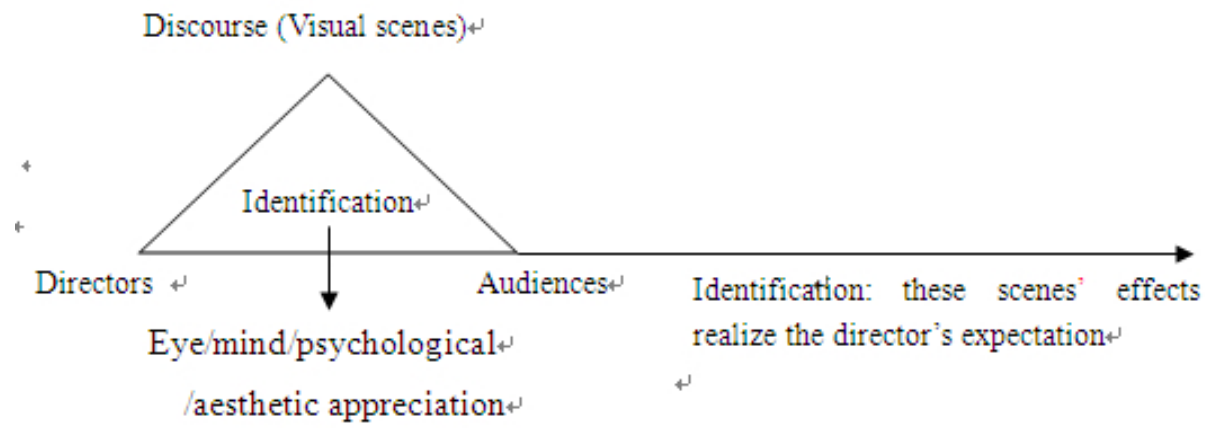

Figure 1. Identification by visual scenes in Avatar

These magnificent scenes can always leave a deep impression on the audiences by displaying the aesthetics to the full. The scenes just like the human's appearance can always arouse people's direct feeling. When you meet a handsome man or a beautiful lady, most of us will judge them by his or her appearance firstly. Therefore, we can see the scene as well as the aesthetics plays an important role in appealing human's eye which can be regarded as Eye Effect. Eye effect normally refers to all kinds of approaches to draw the attention of someone who has consumption capacity and motivation in order to realize the propaganda objective then fulfill the purpose of profit-making. In one word, these scenes satisfy the audiences' needs for aesthetic appreciation.

The director Cameron not only pays attention to beautifying the scene for the sake of his audiences' aesthetic standard, but also uses those fantastic scenes which are beyond the common people's imagination to stir up their curiosity. The people and animals in Avatar are not the same as the ones in real world. The human being in Pandora are more than 2 meters high with a long plait, long tail just like monkeys, with blue skin and so on. The distinguished appearance of the characters can draw the audiences' attention greatly and instantly. Although they are non-verbal signals, they can play an important role in rhetoric. And the director always uses various shooting skills to describe the actors' distinguished features. For instance, long shot is used to give audience a whole image of the $\mathrm{Na}$ 'vi citizen, and then medium shot is applied to show their four fingers, big eyes, feline ears, fleshless faces, long feral snout, and curl tail, etc. These descriptions arouse audiences' curiosity about why the director depicts his characters like that. Human beings are willing to see the following development once their hearts are filled with some curiosities. Of course the director will not let his audiences down because the following plots in this movie will answer human beings' curiosity one by one. For example, the Pandora people are more than two meters high with longer arms and legs because their living circumstances compel them to run quickly and climb mountains or trees agilely. Just as Lloyd F. Bitzer's states in his Rhetorical Situation: "the situation controls the rhetorical response in the same sense that the question controls the answer and the problem controls the solution" (1968, p. 386).

\subsection{Three Basic Ways of Identification in Avatar}

Avatar is considered as a good application of rhetorical skills. The three ways of identification (identification by sympathy, identification by antithesis and identification by inaccuracy) can all be found in Avatar. 


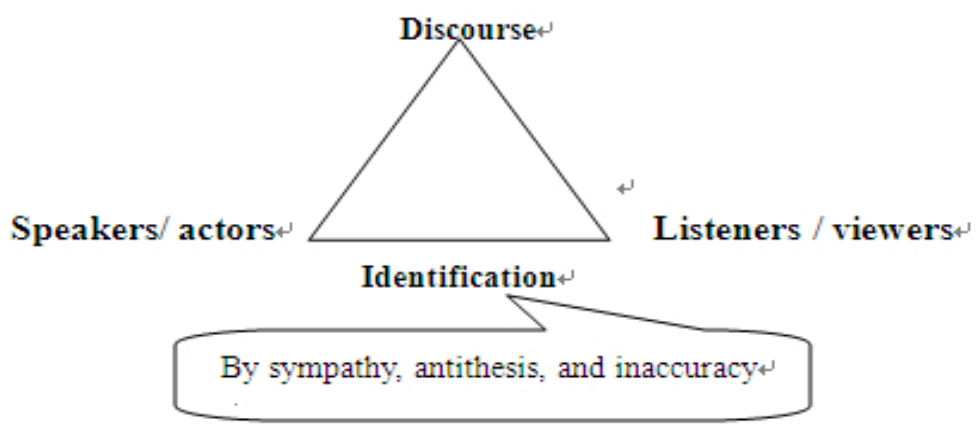

Figure 2. Identification by three basic ways

\subsubsection{Identification by Sympathy in Avatar}

The possibility of identification by sympathy in the movie lies in the fact that the audience's reactions are greatly driven by emotions of the figures in the movie. Therefore, the characters of the movie could identify with their audiences by meeting their expectations and arousing the common emotions from the audience.

In the movie of Avatar, when the cacique's (the chief of the Pandora planet) daughter Neytiri cries sadly over his death as a result of the aggression from the earth, Jack comes to comfort her. But she shouts to Jack and lets him go away because she knows that he is a spy from the earth. The following is the dialogue between the them:

(Voice) Eytukan: Daughter - take my bow. Protect the people.

In his last living moment he places his bow in her hands. She collapses over him, her face crumpling in grief. Jack reels out the smoke. Kneels next to her. face.

(Voice) Jack: I'm sorry - She shoves him away and stands, screaming at him as tears stream down her

(Voice) Neytiri: Get away from me, Jack. Go away! Never come back!

Jack stumbles back as she slumps down by her father's body. Sparks and smoke swirl around him. He watches as - Neytiri kneels, grieving. Slumped over, clutting her stomach. Keening like an animal.

Eytukan is Neytiri's father, how painful she will be when a daughter lost her father. The audiences' sympathy is aroused by the heroin's behavior, such as hysterical sound and tears streaming down cheeks when she is kneeling besides her father. In this way, they will put themselves in the place of the girl and identify with her, hoping she can take revenge for her father. At the same time, this scene also motivates Jack to fight for justice rather than for the greedy earthmen. Besides, this is what the audiences expect, so the moving scene achieves identification with actors themselves and the audiences in the front of the screen. In other words, it is the sympathy that persuades both the listeners in the movie (Jack) and the listeners out of the movie (the mass audiences) to support the Pandora people in misery.

There is another instance that can interpret the identification by sympathy. The actress Grace is an invader at the very beginning, but later on when she finds the earthmen's behaviors are too brutal to bear while the Na'vi people are indeed very innocent and really deserve sympathy, she changes her attitude toward them from persecution to assistance. It is the sympathy aroused in Grace's heart that makes her stand by the Pandora. Persuasion occurs when Grace accepts the identification which is conveyed by the $\mathrm{Na}$ 'vi people as it evokes consubstantiality between them. The following figure can make across the discussions above like this: 


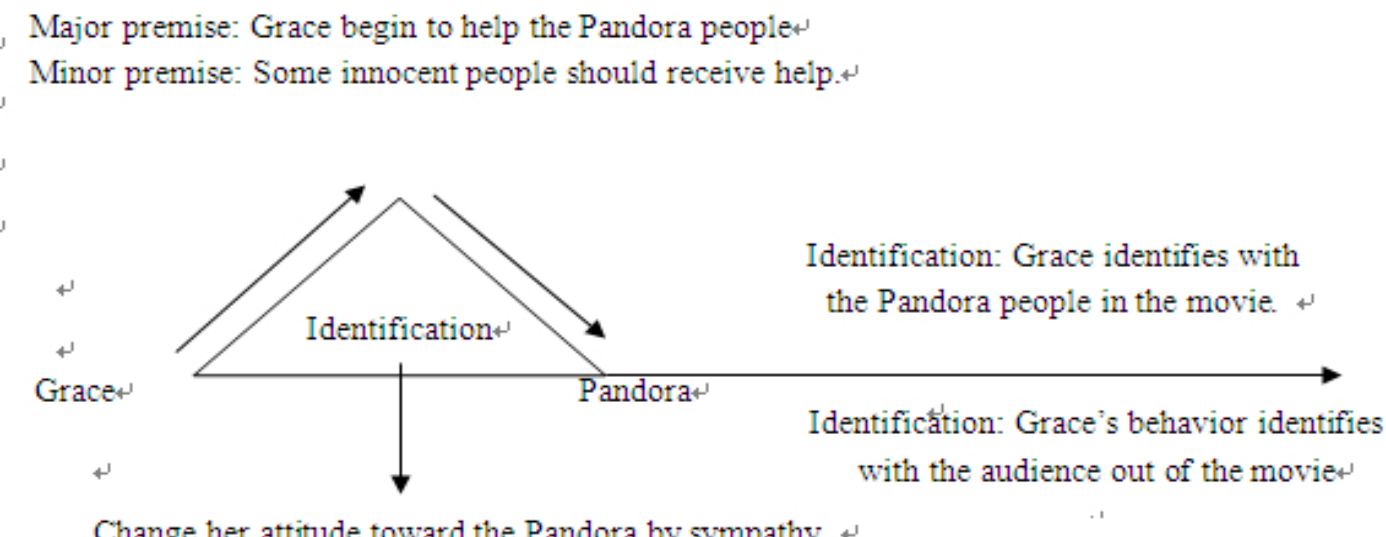

Change her attitude toward the Pandora by sympathy

Figure 3. Identification by sympathy in Avatar

This is a process of psychological alteration. I feel considerably gratified when I see Grace changes her attitude to Pandora, because her behavior touches my heart and meets what I expect. From the aspect of rhetoric, the Pandora's pathetic condition evokes Grace's sympathy, and unconsciously persuades her to support them. Consequently, the purpose of the directors' design is realized, which identifies with the Pandora by the way of sympathy. It's a good example to illustrates Burke's sentence: "if a speaker and his audience share the same attitudes or values, identification will be possible realized in the end".

\subsubsection{Identification by Antithesis in Avatar}

Identification by antithesis is a form of achieving congregation through segregation. It means that the ever opposing groups may make an alliance against a common enemy or common problem. Just as Burke says: "It involves the workings of antithesis, as when allies who would otherwise dispute among themselves join forces against a common enemy." (Burke, 1972, p. 36)

In Avatar, Jack stands by the earthmen at first. But later on, when the earthmen attack the Pandora citizens ferociously with Jack, the Pandora citizens realize Jake is their enemy not friend. The Pandora residents bind Jack to a tree and want to kill him as a revenge. The cacique's wife does not believe he is as bad as in the others' eyes. Thus she unties him and tells him, "If you are one of us, help us." Jack uses his behavior of resisting their common enemy to prove that he identifies himself with the Pandora people instead of the merciless and brutal earthmen. As Burke says, identification is the starting point of persuasion as well as the end of persuasion. According to Jack's last performance, we can see Jack has been persuaded by the Pandora people to achieve identification with them.

Jack and Pandora people are enemies at the very beginning, but Jack's attention is directed to the evil of the earthmen and the identification between Jack and Pandora people is achieved on the basis of their common enemy. In the end they make an alliance against their common enemy (earthmen).

We can use the following diagram to illustrate the complicated relationship among them:

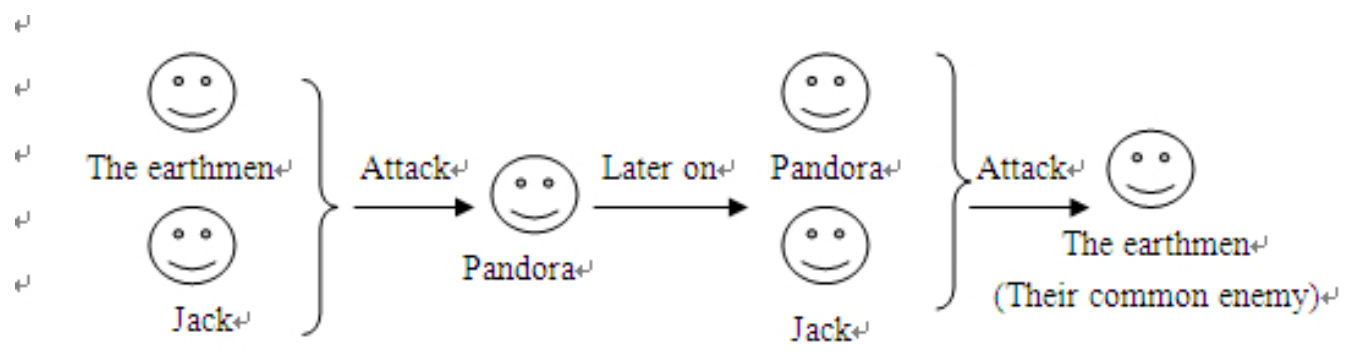

Figure 4. The changed relationship among these three groups 
The following communication triangle interprets how they are identified by antithesis:

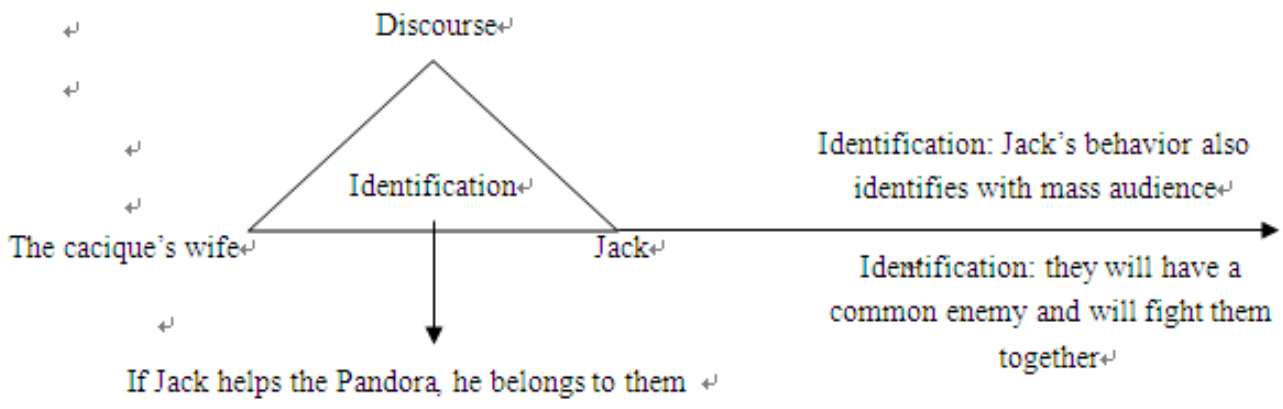

Figure 5. Identification by antithesis in Avatar

From the above figure, we can conclude the actors in movie realize the identification with Jack by the means of satisfying their safety needs. According to Abraham Maslow, people's needs are divided into five levels from basic to aesthetic as follows:

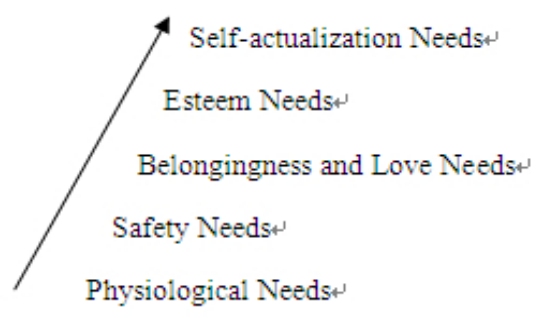

Figure 6. Human needs hierarchy

Specifically speaking, people's needs are divided into physiological needs, safety needs, belongingness and love needs, esteem needs and self-realization needs. Physiological needs are the needs for things that ensure basic survival, such as food, clothing, shelter, and transportation. Safety needs ensure a safe and secure life free from harm or danger of illness, loss of property or life. Social needs are the needs for social belonging and social interaction, and the need for love, affection and acceptance. Most people need to be admitted as a social citizen. Esteem needs are the needs of being respected for their knowledge, wealth, achievement, social position, etc. Self-actualization needs are the needs for whatever helps people fully realize their potential and further develop their personal capabilities (Foss, 1985, pp. 43-47).

In movie of Avatar, Pandora people are facing the danger of losing their lives and hometown. In other words, their safety needs are in danger. We know that the promise of meeting a certain need is an effective appeal. Jack uses his performance to carry out his promise of helping them. By this means, Jack proves that he belongs to Pandora. Meanwhile, Jack can meet his belongingness needs. Besides, he can take him as a symbol of justice and in a further step to achieve the self-actualization needs by helping others. These human needs which can be seen as the motivation of their performance are the factors that promote the actors to identify with the other actors in the movie and the mass audiences out of the movie as well as the director himself. In the previous discourse, we can also describe it from the perspective of enthymeme which goes just like this:

Major premise: Jack decides to help the Pandora people. (Identification in attitude)

Minor premise: In Pandora, the people who protect the Pandora in the war belongs to them. (Discourse)

Conclusion: Jack belongs to Pandora. (Identification)

It can also be transferred into the basic structure of Toulmin model of argument: 


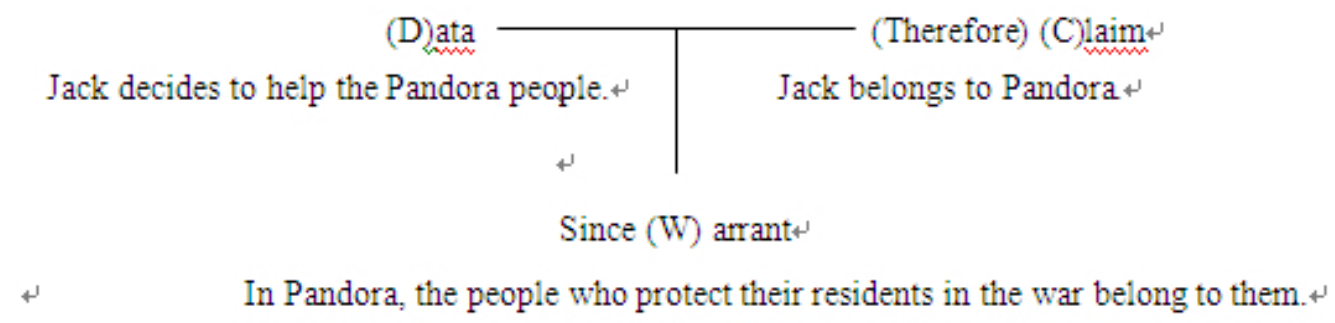

Figure 7. Toulmin's Model of argumentation in Avatar

\subsubsection{Identification by Inaccuracy in Avatar}

Identification might be realized unconsciously. It is often "a very powerful way of identification deriving from 'the situation in which it goes unnoticed' (Burke, 1972, p. 28). The advertisement about Marlboro cigarette is a classical example to interpret identification by inaccuracy. Smokers may unconsciously have an illusion that they will also be cool and charming like the image in the advertisement by watching it. At this time, smokers identify with the advertisement and would like to buy Marlboro cigarette.

Similarly, there also exist some models of identification by inaccuracy in Avatar. Now let's study how the earthmen mistakenly identify the power of advanced weapons with their own ability through the following scene. The director can express the earthmen's ignorance and simultaneously tear down the images of these villainous earthmen through their mistaken identification. By this means, the director artfully shows the heroes' courage.

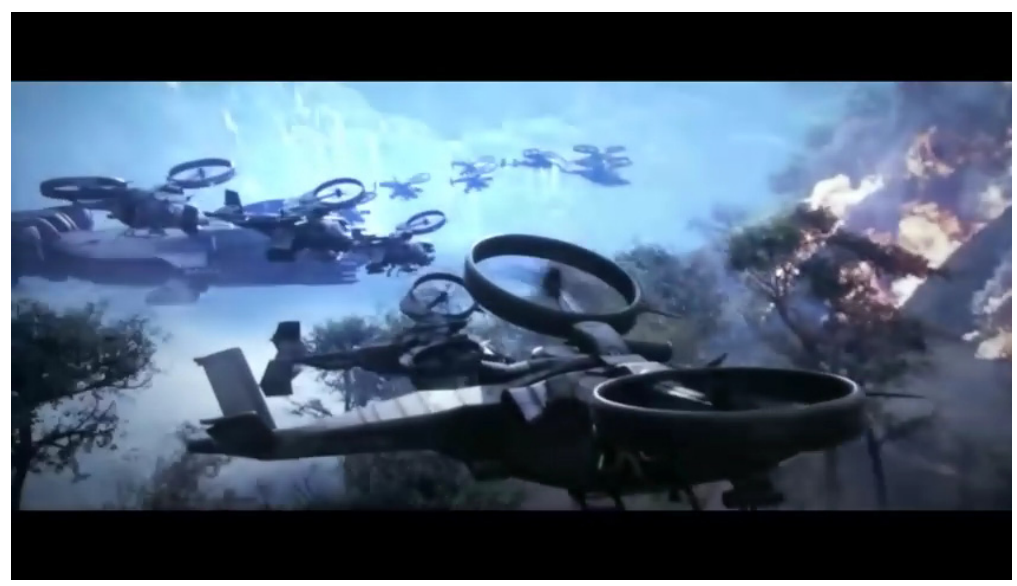

The following diagram is the model of identification by inaccuracy.

The following diagram is the model of identification by inaccuracy.

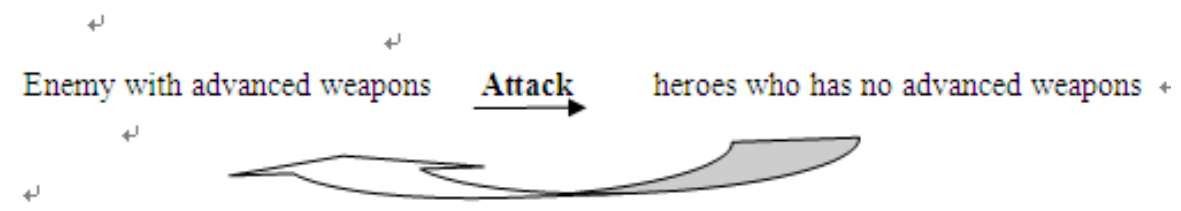

But the heroes finally win the villain by their courage and union strength

Contrary to the earthmen's thought that they are powerful

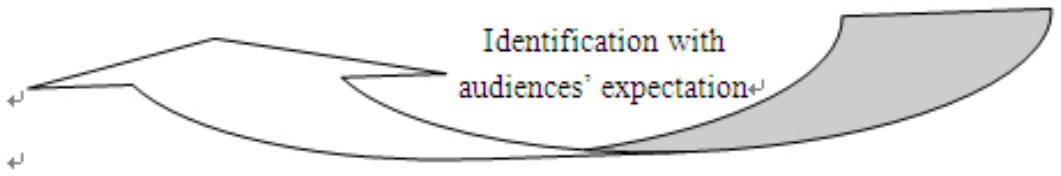

Improve the heroes' image via the enemies' inaccuracy identification

Figure 8. Identification by inaccuracy in Avatar 
According to this figure, it is obvious that the earthmen with advanced weapons believe that they are powerful. Therefore, they attack the Pandora people fiercely. Nevertheless, the Pandora people are not frightened by the earthmen's superficial power but bravely combat them. Besides, the need for safety is another important reason for their courageous behavior. Anyway, human beings have imponderable potential. As long as they come across some emergent events, such as the danger to their life, they may explore their potential to the full and take some measures to protect themselves. The Pandora people's performance make the earthmen realize that owing the advanced weapon does not mean owing the real superiority. The Pandora people's courageous behavior succeeds in persuading their audience to accept the director's plots which is designed to improve the heroes' image via the enemies' inaccuracy identification. Lastly, the directors, actors and audiences identify with each other by the directors' arrangement, actors' performance as well as audiences' response.

\section{Conclusion}

Avatar is a great movie which has attracted quite a number of audiences all over the world. In other words, it successfully persuades the people around the world to watch it. Therefore, many movie critics and rhetorical scholars are studying it from different aspects. Nevertheless, most of them do not analyze it from the perspective of western rhetoric. Theoretically speaking, the author combines this movie with western rhetorical strategies together to study how Avatar get a great success and then concludes how the directors, actors and the audiences gain the identification with each other.

This paper first presents a systematic introduction of Kenneth Burke's rhetorical theory of identification and its three strategies, namely, identification by sympathy, antithesis and inaccuracy, which is a great development of new rhetoric from persuasion to human motives. The core of new rhetoric is the concept of identification, which can induce a partially 'unconscious' factor in appeal (Burke, 1966, p. 538) and arouse the common emotions, attitudes and values between the speaker and listener.

Next, the author uses the previous rhetorical systems to analyze the examples. Different from other examples, the author finds that the movie can be studied from various perspectives because it includes so many orators. So to speak, anything in the movie can be seen as an orator. Those orators can be persuaded by each other profoundly and the identification between them could be achieved. Based on the previous theory study, the realization of identification among the directors, actors and audiences is expounded vividly in Avatar. Firstly, the beautiful scenes in Avatar attract the audiences' attention, which sets up a steady basis for the director's purpose of identifying with audiences. Secondly, the author analyzes the Avatar from the three basic ways of identification and finds that the identification by sympathy, antithesis and inaccuracy can as well be applied in Avatar. The identification among the characters of the movie and the identification among directors, the actors and the audience could finally be achieved, which could meet the expectations of the movie and gives a better enjoyment to the audience.

Through a rhetorical analysis of Avatar, we arrive at a conclusion that identification strategies play an important role in the movie, which also make it easy for the audience to accept what the movie conveys and evoke the resonance between them.

All in all, through these studies, the author wishes to make some contributions to the development of rhetorical theories and offers a new perspective of the appreciation of sci-fi movies.

\section{References}

Bitzer, L. (1968). The Rhetorical Situation. Philosophy and Rhetoric, 1, 1-14. University Park: The Pennsylvania State University Press.

Burke, K. (1962). A Grammar of Motives. Berkeley: University of California Press.

Burke, K. (1966). Language as Symbolic Action: Essays on Life, Literature and Method. Berkeley: University of California Press.

Burke, K. (1969). A Rhetoric of Motives. Berkeley: University of California Press.

Burke, K. (1972). Dramatism and Development. Barre, MA: Clark University Press.

Foss, S. K. (1985). Contemporary Perspectives on Rhetoric. Prospect Heights, Illinois: Waveland Press.

Ning, D. (1998). Contemporary Western Rhetoric: Critical Paradigms and Methods. Beijing: China Social Science Press. 


\section{Copyrights}

Copyright for this article is retained by the author(s), with first publication rights granted to the journal.

This is an open-access article distributed under the terms and conditions of the Creative Commons Attribution license (http://creativecommons.org/licenses/by/3.0/). 